\title{
VICENTE HUIDOBRO, POESÍA DE DOS TIEMPOS: "PERIT UT VIVAT"
}

\author{
POR \\ CedomiL GoIc \\ University of Michigan
}

Entre los nueve poemas que se recogen en la "plaquette" El espejo de agua (1916) de Vicente Huidobro, destacan tres por su original significación y su importancia en relación a la obra ulterior del poeta. Estos son "Arte poética", "El espejo de agua" y "Año nuevo". Los otros seis se mueven en un ámbito poético común de resonancias recientes, extrañamente próximos y distantes a la vez de los poemas de la poesía hispanoamericana y francesa del mismo tiempo. Con ellos tienen en común el código de la casa, como figuración del límite, y la sugestión de la inminencia como forma de expresión y de imaginación del tiempo. Más allá de la clausura de la casa y de la clausura del texto, los poemas de Huidobro se abren desde el espacio restringido, sombrío o mortal, a espacios abiertos a través de las ventanas o los espejos. Los poemas que destacamos plasman un mundo de objetos y de actitudes nuevas, en las que la novedad consiste en la modificación de motivos convencionales o nuevamente conocidos, que transforman los datos - lo dado- con la imaginería creacionista. Es decir, con una original agresividad desviatoria de las creaciones verbales, dentro del común espíritu de vanguardia. Todo ello permite observar desde el momento inicial de la participación de Huidobro la indudable singularidad de su imaginación del tiempo, que lo distingue con la visión del instante en que confluyen y se separan dos tiempos, en medio de la comunidad de concepciones y preferencias de la vanguardia europea.

Es interesante consignar que de estos tres poemas, los dos primeros, "Arte poética" y "El espejo de agua", no se traducen en Horizon Carré; más aun, se los sustituye aparentemente por "Nouvelle chanson" y "Glace", poemas que modifican la postulación metapoética remplazando el género de decir prescriptivo de "Arte poética" por uno de anunciación del canto nuevo, a tono con la poesía de lo inminente, e introduciendo el humor y la autoironía en el poema "Glace", y jugando con las contraposiciones de la pura reflexividad y la profundidad del tránsito de los espejos. Los otros siete serán traducidos y dispuestos conforme al nuevo espacialismo y con variado uso de líneas en altas. "El espejo de agua" encontrará una traducción, "Miroir d'eau" en Saisons Choisies (1921), con que se cierra y abre un momento de cambio en la poesía de Huidobro. Fin de las galanuras del espacialismo y apertura hacia un énfasis dadaísta de extremosidad desviatoria de la imagen y de humor y juego de sus libros de 1925. "Arte poética" no será traducida y el manuscrito que conservamos no llega a dar buen fin a su esfuerzo, agotado en tentativas frustradas. 
Dejaremos de lado, por ahora, el análisis de "Arte poética", para ocuparnos de los otros dos poemas mencionados.

"El espejo de agua" es un poema de metro irregular, dispuesto en cuatro dísticos y un terceto de versos de $10,11,12$ y 13 sílabas y rima parcial, -o-e en los versos 1 y 3 , -a-o en los versos pares, $2,4,8$, salvo en el segundo dístico y en el terceto final en donde el primer verso, el verso 9, rima en -a-o con aquéllos; los versos 5 y 6 van pareados con rima parcial -a-a, y lo mismo, con otra rima, -e-o, los versos 10 y 11, es decir, ABABCC, BBBDD.

\section{EL ESPEJO DE AGUA}

Mi espejo, corriente por las noches, Se hace arroyo y se aleja de mi cuarto.

Mi espejo, más profundo que el orbe Donde todos los cisnes se ahogaron.

$5 \quad$ Es un estanque verde en la muralla $\mathrm{Y}$ en medio duerme tu desnudez anclada.

Sobre sus olas, bajo cielos sonámbulos, Mis ensueños se alejan como barcos.

De pie en la popa siempre me veréis cantando.

10 Una rosa secreta se hincha en mi pecho $\mathrm{Y}$ un ruiseñor ebrio aletea en mi dedo.

El poema se dispone en dos segmentos, uno, paralelístico, de ordenación anafórica: Mi espejo / Mi espejo / <Mi espejo>, que comprende los tres primeros dísticos, reforzados por el sistema de la rima. El otro, mediante determinaciones espaciales que establecen un entorno de planos definidos: sobre, bajo, de pie en la popa, en mi pecho, en mi mano, despliega, distinguiendo e incluyendo diversos planos o niveles en una visión metapoética.

El título propone los términos implícitos en las transformaciones que despliega el poema. Una es la reflexividad del espejo, la otra es la liquidez y la inmovilidad del espejo de agua. La mera reflexibilidad va a ser sometida a una conversión o transformación por vía de la liquidez y la profundidad escasa en la movilidad, la dimensionalidad y la profundidad infinita que sobrepuja la extensión del orbe.

Mi espejo, corriente por las noches, Se hace arroyo y se aleja de mi cuarto.

Mi espejo, más profundo que el orbe Donde todos los cisnes se ahogaron.

Es un estanque verde en la muralla $\mathrm{Y}$ en medio duerme tu desnudez anclada. 
Establecida queda la identidad del medio, espejo, corriente, sueño, marcado por la liquidez, el dinamismo, la expansión dimensional corriente-arroyo-mar, mediante la profundidad cósmica enunciada por el sobrepujamiento - "más profundo que el orbe"y la implicación marina del entorno.

En éste, el hablante representa, en un primer plano, de líquida fluxión profunda, sobre el agua - "Sobre sus olas"- el plano segundo en que el objeto de sus ensueños, su imaginación nocturna concretada, duplicándose en ellos, se libera en el viaje y la aventura:

Mis ensueños se alejan como barcos.

Luego, en un tercer plano de inclusión, se contempla como piloto y viajero,

De pie en la popa siempre me veréis cantando.

Para exhibir a continuación y finalmente, en desdoblamiento de nuevo signo, lo que viene a ser la consecuencia o la efectividad misma del canto, inclusión doble de cuarto grado, en esta serie de encuadres:

Una rosa secreta se hincha en mi pecho

$\mathrm{Y}$ un ruiseñor ebrio aletea en mi dedo.

Reiterando o recogiendo las circunstancias descritas en el marco anterior, encuadra dos acciones: una, la que ve alejarse los ensueños-barcos - through the looking glass; la otra, la que sitúa, al cantor en ellos en posición de conducción o mando, y, finalmente, la que describe o proclama el canto-navegación-creación, por la cual todos tres se identifican. El sistema es de amplificación anafórica que ordena dinamismo y profundidad sucesivamente. Identificada la conciencia con la liquidez, adquiere el carácter dinámico y profundo de los sueños, concretados primero - sobre las olas - en concreción objetiva de la creación como naves, como barcos; en él, de pie en la popa el cantor; y su canto haciendo florecer el entusiasmo de la belleza en su pecho y el ave poética exaltándose eufórica en el dedo prestidigitador y mágico del sueño poético.

El sistema descriptivo se construye sobre +/-móvil, +/-onírico, +/-profundidad en gradación creciente (espejo / estanque / corriente, arroyo, mar). Así "anclada", por implicación de la movilidad del medio líquido, en su primer segmento remite al reflejo permanente en el flujo y la profundidad de la imaginación del sueño. En el segundo segmento, +/-onírico, +/-móvil, +/-marino (olas, barcos, cielos, popa, yo marinero cantor, Argonauta o Arión), despliega la pluralidad de planos de los contenidos transformados y las virtudes del canto creado enumerados en los versos finales.

El lenguaje poético da lugar a una personificación novedosa del hablante o de su conciencia al par de la transformación mágica del espejo. La determinación posesiva corresponde a la primera, segunda y tercera persona (Mi $/ \mathrm{mi} / \mathrm{Mi} / \mathrm{Mis} / \mathrm{mi} / \mathrm{mi}$, tu, sus). La pronominalización es siempre declinada en la primera persona singular (me) y segunda plural (<vosotros $>$ ) en la apelación. Las otras determinaciones son principalmente locativas y modales, delimitan entornos y planos inclusivos y modalizan transformando lo 
habitualmente reflexivo e inmóvil en pluralidad de imágenes y flujo libre de los límites del cuarto.

La predicación destaca la creación verbal de la imagen "desnudez anclada" (+/abstracto), y de las aposiciones modalizadoras, "Mi espejo, corriente por las noches", "Mi espejo, más profundo que el orbe" (+/-inmóvil, +/-profundo, +/-finito), que realizan la conversión dinamizadora. La predicación verbal, "Se hace arroyo y se aleja de mi cuarto" ( $-/$ líquido, $+/$-móvil), activa la transformación y la libertad; la predicación nominal " $<\mathrm{Mi}$ espejo $>$. Es un estanque verde en la muralla" (-/+líquido,+/-inmóvil, +/-vertical) fuerza al extremo la impertinencia semántica. Por último, la comparación "Mis ensueños se alejan como barcos", de impertinencia del comparado (+/-libertad, +/-móvil, -/+concreto) provee la transformación final apoyada en la efectividad del verbo - "se alejan" - que opera en los dos segmentos las transformaciones libres de la imaginación nocturna ampliada en los verbos "hincha" y "aletea" con que se animan sus productos vivos.

El temple de ánimo se percibe de inmediato como autogozo creador, eufórico y exaltado, de polaridad positiva bien marcada en lo que afirma y de intensidad mayor particularmente en el epifonema en que concluye. En lo que niega, se complace en la destrucción cumplida en una autoapreciación de la profundidad superior, llevada al límite, de la nueva imaginación.

El género de decir es aseverativo, se extiende en la constatación, la confirmación y la proclamación del dinamismo de la conciencia y del milagro poético o creador, autocontemplado en la visión reflexiva de la imaginación poética nocturna.

La matriz del poema es la libre transformación de la conciencia por la fantasía onírica nocturna, la que juega entre la liquidez y fluidificación del espejo, y la inmovilidad, entre el dinamismo de la imaginación profunda y la pura reflexividad invariable de las imágenes en el espejo.

En esa conciencia líquida, cambiante, libre y profunda, de profundidad cósmica, se ahogan los cisnes, cancelando los signos modernistas de la belleza. El nuevo reflejo en el espejo es el de la belleza desnuda, en que lo estático e inmóvil se destruye por la imagen "desnudez anclada", la que permanece en el cambio, una y desnuda, símbolo constante de lo bello. La transformación de la conciencia nocturna que liquida el sólido espejo, germinal pero quieto, la imagen de una conciencia puramente reproductiva se transforma en creativa y maravillosa, adquiere un dinamismo de agua en movimiento y profunda, de contorno sobrepujante, infinito y destructor.

El subtexto perceptible en esta innovadora visión poética es, en palabras de William James, "the stream of consciousness", o, si se quiere, la "durée", la duración de la consciencia bergsoniana, encarnación de "notre passé inmmédiat et de notre avenir imminent", memoria $\mathrm{y}$ anticipación aplicadas a la descripción de las metamorfosis de la imaginación nocturna.

Contexto del ciclo del libro o "plaquette" lo proporciona, como se ha dicho anteriormente, el código de la casa (espejo, cuarto, muralla) que pone los términos del espacio limitado desde donde se aleja o escapa y libera la imaginación nocturna a un espacio libre o infinito.

Poema metapoético, poema que habla de la poesía y de su factura creacionista, es decir, de su transformación del mundo en el proceso de hacerlo y de plasmarlo efectivamente distinto, mágico y exaltado. En él, "De pie en la popa siempre me veréis cantando" es una 
figura de disposición en abismo (mise-en-abyme), que duplica en un verso la acción del poema entero y la persona del hablante poético, piloto Argonauta de la aventura poética que se aleja de lo conocido, marinero mágico como Arión que acomete hazañas de prodigioso dominio del universo, encantando con su canto.

En su conjunto, el poema propone dos tiempos: uno de destrucción y otro de proposición creadora actual y mágicamente nueva. Entre ambos media estática la visión reflexiva del estanque que el locativo - "en la muralla"- hace insólita y que duplica la visión inerte y venusina de la belleza, detenida allí donde todo fluye. Los términos de la estaticidad están dados por el código de la casa - espejo, cuarto, muralla — que sirve para establecer el entorno ordinario de donde escapa el libre juego de la imaginación creadora en el ensueño dirigido por el piloto cantor que es conducido y conduce. El mismo transforma creadoramente un código heredado haciendo que la innovación devore lo conocido al apropiarse de los motivos modernistas y tradicionales - cisne, desnudez, ensueños, rosas, ruiseñor: "Donde todos los cisnes se ahogaron", "Y en medio duerme tu desnudez anclada", "Mis ensueños se alejan como barcos", "Una rosa secreta se hincha en mi pecho, / Y un ruiseñor ebrio aletea en mi dedo", son las figuras donde viven y mueren para renacer transformados los viejos tópicos modernistas. El poema responde inmediatamente al "Arte poética" y a la poética anticipada en el pensamiento de Huidobro. Se adelanta en la transformación de los motivos de lo interno y lo externo, en el alejamiento de los límites conocidos de los objetos, en el activo distanciamiento y la enunciación de lo inhabitual, por virtud de la cancelación de lo habitual y merced a la acción creadora y trasmutadora.

El poema "Año Nuevo", ocupa el penúltimo lugar en la serie de nueve poemas de $E l$ espejo de agua. Se ordena en seis grupos estróficos de 4/2/1/2/1/2; con versos de 13, 12, 11,10 sílabas y versos de 4 y 6 sílabas, con rimas asonantes dispersas, -e-o, -ea, -a-a, y consonantes, -ores, -io, y un verso enteramente suelto, en otras versiones escrito en números.

El título apunta al instante presente en que el nuevo año se inicia, escoge una instancia jánica y opera como la matriz de una imaginación del tiempo escindido que ilustra el comienzo del año y revela en la visión cinematográfica y su entorno los determinantes temporales de presente y pasado y espaciales de dentro y fuera.

\section{AÑO NUEVO}

El sueño de Jacob se ha realizado.

Un ojo se abre frente al espejo

Y los hombres que bajaban a la tela

Arrojaron su carne como un abrigo viejo.

$5 \quad$ La película mil novecientos dieciséis

Sale de una caja.

La guerra europea. 


\section{Llueve sobre los espectadores \\ $\mathrm{Y}$ hay un ruido de temblores. \\ 10 \\ Hace frío. \\ Detrás de la sala \\ Un viejo ha rodado al vacío.}

El poema presenta dos segmentos: el compacto inicial que desarrolla la enunciación de la realización de un portento, descrito sumariamente en paralelismo con el subtexto bíblico. El segmento siguiente describe el proceso y contenido de lo verificado. La equivalencia del tiempo presente en su fluxión y el montaje de las circunstancias que componen la sala de cine - tela, película, espectadores, sala - distinguiendo un adentro y un afuera que se corresponden con lo que acontece en el presente, y el pasado inmediato. El poema identifica el presente con el rodar de la película y el pasado con la imagen de un viejo que rueda al vacío, figura emblemática del año viejo vs. el Año Nuevo de acuerdo a una imagen gráfica y publicitaria del inicio del nuevo año.

1.

El sueño de Jacob se ha realizado

El verso hace referencia al Génesis 28, 10-16, y al portentoso sueño en el cual Jacob ve la escalera que une la tierra con el cielo por donde suben y bajan ángeles y desde lo alto de la cual Jehová le habla. Lo que el hablante anuncia es la verificación o cumplimiento nuevo y milagroso de la comunicación de dos mundos.

¿En qué consiste la duplicación moderna del milagro bíblico?

2.

Un ojo se abre frente al espejo

$Y$ las gentes que bajaban a la tela

Arrojaron su carne como un abrigo viejo.

La nueva visión se representa como el haz luminoso que se proyecta sobre el telón, visto como espejo duplicador de una imagen trasmutada, es decir una nueva visión. En ella se patentiza la trasmutación de los seres reales cuya imagen retiene la cinta cinematográfica, como un descenso, tránsito que comunica dos mundos: el de la imagen cinematográfica y del mundo real que reproduce. En ese tránsito acontece la trasmutación señalada. Los seres humanos pierden su carne corporal, se desprenden de su volumen como de un desecho para adquirir su pura forma de imágenes. En ello concurren también las notas contrapuestas de lo nuevo y lo viejo. Los signos de renovación de los tiempos acompañan el milagro de la retención - transmutación - cinematográfica que ha agregado el movimiento a la simple retención estática de la fotografia, pero ha desprovisto de bulto corporal a los hombres. Los seres nacen así a una nueva condición o entidad imaginaria, se desprenden del cuerpo como de lo viejo y desechable. Se anticipa aquí el elemento duplicado en los versos finales del poema que evidencian el broche semántico de lo nuevo y lo viejo. Formulación originalísima y temprana del fundamental tópico de "perit ut vivat" huidobriano. 
El temple expresado es el de la conmoción maravillada del acontecimiento que incluye el gozo creador de la comprensión poética agregado al anterior.

3.

La película mil novecientos dieciséis

Sale de una caja

Se reduce el portento a su real ocurrencia. Comienza a proyectarse la película 1916 desde la proyectora cinematográfica. La referencia a la caja deja vibraciones sugestivas de "caja de sorpresa" o "caja de Pandora". Lo que ahora se contempla y describe es constatación teñida de mágica sorpresa. Comienza el año 1916, equivalencia del tiempo y de la película.

4.

La guerra europea

Enuncia el contenido mismo de lo que se representa en el tiempo-película. Las notas siguientes marcan signos negativos, indicios de un tiempo invernal y angustioso, comunicadores del temple inducido por las circunstancias aciagas.

5.

Llueve sobre los espectadores

$Y$ hay un ruido de temblores

Hace frío.

Estas circunstancias agregadas son efectos cinematográficos que se proyectan como efectos reales sobre los asistentes al cine, pero acaban por marcar los signos aciagos de aquel tiempo.

6.

Detrás de la sala

Un viejo ha rodado al vacío.

Finalmente, se contrapone a lo interno, a lo que los espectadores tienen delante y al ámbito mágico de la sala, lo que está fuera o detrás de él. Fuera, entonces de la experiencia del presente mágico y doloroso que viven los espectadores, se puede constatar un hecho que adquiere un carácter marginal. El año viejo ha pasado definitivamente, cancelado y muerto. Con lo que se construye el poema entero en la contraposición y la correspondencia de nuevo/viejo, presente/pasado, adentro/afuera, vida/muerte. La imagen del presente en el cual concurren la cancelación del pasado y el nacimiento o anuncio de un nuevo tiempo se adelanta aquí a elaboraciones más complejas, constantemente variadas, y más extensas del tópico fundamental y dominante en la poesía ulterior de Huidobro, desde Ecuatorial a sus Últimos poemas. 


\section{NOTA BIBLIOGRÁFICA}

Ediciones: El espejo de agua (Buenos Aires: Ediciones Orión, 1916) 16 páginas, sólo aparece numerada la páagina 8 por no ser cabeza de poema, $22 \times 14 \mathrm{cms} ; 2^{\mathrm{a}}$ edición (Madrid: Pueyo, 1918), sin paginar, 14 x $20 \mathrm{cms}$; edición facsimilar de la edición príncipe, Peña Labra. Pliegos de Poesia, 12 (Madrid 1974), y se recoge en las ediciones de Obras selectas (Santiago, 1957); Obras completas (Santiago: Zig-Zag, 1964 y Santiago: Andrés Bello, 1976).

Traducciones. De los nueve poemas de la edición príncipe se traducen en Nord-Sud y pasan a Horizon Carré, "El Hombre Triste", "El Hombre Alegre", "Nocturno", "Año Nuevo" y "Alguien iba a nacer", a ellos se sumarán en este libro, "Minuit" y "Automne". Saisons Choisies (1921), recoge "Le Miroir d'eau". De "Nocturno", "Minuit" en la versión francesa, hay versión en español, Índice de poesía americana nueva (Buenos Aires: El Inca, 1926) que sigue la disposición espacial de la francesa. Existe un manuscrito mecanografiado, en inglés, "Water Mirror". Existen, igualmente, manuscritos de "Año Nuevo", "Arte poética", y versiones espacializadas, retraducciones al español de las versiones francesas de Horizon Carré, de "El hombre triste" y "El hombre alegre". Hay también un manuscrito, en español, a todas luces anterior a la versión francesa, correspondiente a "Nouvelle Chanson".

Estudios:

Admussen, Ricard L. y René de Costa. "Huidobro, Reverdy, and the editio princeps of El espejo de agua", Comparative Literature 24 (1972): 163-175. Reproducido por René de Costa, editor Vicente Huidobro y el creacionismo. Madrid: Taurus, 1975, 249-264.

Concha, Jaime. Vicente Huidobro. Madrid: Jucar, 1980, 44-58.

Costa, René de. "Nota bibliográfica sobre la edición facsímil de El espejo de agua". Peña Labra 12 (1974) 3-7.

Cuneo, Ana María. “Análisis de 'El espejo de agua', poema de Vicente Huidobro”, Revista Chilena de Literatura 8 (1977) 67-82.

Goic, Cedomil. La poesía de Vicente Huidobro (Santiago, 1956), 2a edición 1974.

Hahn, Oscar. "Vicente Huidobro o las metamorfosis del ruiseñor". Revista Chilena de Literatura 40 (1992) 97-103.

Quiroga, José. "El espacio del autor: Huidobro en sus palabras", Revista de Estudios Hispánicos 27 (1993) 19-36.

Rutter, Frank. "Huidobro y El espejo de agua: nuevas observaciones". Insula 32 (1977) 1 y 12.

Truel, Juana. "La fecha de publicación de El espejo de agua de Vicente Huidobro: análisis de una polémica". Lexis 2 (1978) 71-86.

"En torno al "Arte poética" de Vicente Huidobro". Lexis 5 (1981) 125-132.

Valbuena Prat, Ángel. Historia de la Literatura Española. $3^{\mathrm{a}}$ edición. Barcelona: G. Gili, 1950, III, 608-616.

Wood, Cecil. The creacionismo of Vicente Huidobro. Frederickton, NJ: York Press, $1978,62-94$.

Yúdice, George. Vicente Huidobro y la motivación del lenguaje. Buenos Aires: Galerna, 1978, 26-27, 34-39. 